\title{
La regulación de la filiación derivada de las técnicas de reproducción asistida en la Argentina: voluntad procreacional y consentimiento informado*
}

\author{
Mariana lturburu* \\ María Martina Salituri Amezcua** \\ Mariana Vázquez Acatto***
}

\section{RESUMEN}

En el presente artículo se profundiza sobre la experiencia argentina que regula las técnicas de reproducción humana asistida como fuente autónoma de filiación en el Código Civil y Comercial de la Nación vigente desde mediados del 2015. El elemento determinante en este tipo filial es la voluntad procreacional manifestada en el consentimiento previo, informado y libre prestado ante el centro de salud, independientemente de quién haya aportado los gametos.

PALABRAS CLAVE: Técnicas de Reproducción Humana Asistida, Filiación, Voluntad ProcreacionalConsentimiento Informado

\section{ABSTRACT}

This article explores the Argentine experience that regulates assisted human reproduction techniques as an autonomous source of affiliation in the Civil and Commercial Code of the Nation in force since mid 2015. The determining element in this filial type is the procreative will expressed in the prior, informed and free consent, before the health center, independently of sperm donor.

KEY WORDS: Assisted human reproduction techniques, affiliation, procreative will, informed consent

\footnotetext{
* Artículo recibido el 30 de agosto de 2016 y aceptado el 5 de noviembre de 2016

** Miembro de CATHRA (Comisión Asesora en Técnicas de Reproducción Asistida), Argentina. marianaiturburu@ gmail.com

*** Docente de la Facultad de Derecho de la Universidad Nacional del Centro de la Provincia de Buenos Aires (Unicen), Argentina.martinasalituri@hotmail.com

**** Abogada de la Dirección de Asuntos Legales de la Secretaria Nacional de Niñez, Adolescencia y Familia, Argentina.marianavazquezacatto@hotmail.com
} 


\section{SUMARIO}

1. Introducción

2. Antecedentes

3. Técnicas de reproducción humana asistida y voluntad procreacional

4. La regulación

5. Desafíos

6. Cierre

\section{Introducción}

Desarrollaremos a continuación los antecedentes normativos y jurisprudenciales que dieron lugar a la regulación de las técnicas de reproducción asistida (TRHA) como fuente de filiación, qué es lo que prevé el sistema filiatorio en relación con ellas, la valoración de la voluntad procreacional en la determinación de esta relación jurídica y los requisitos para su efectiva manifestación. Finalmente, dejaremos planteados aquellos conflictos que atraviesa la regulación, así como las cuestiones que se encuentran pendientes de resolución por parte de la norma.

\section{Antecedentes}

La importancia de las técnicas se visibilizó en el plano jurídico de Argentina a partir del año 2010, con la sanción de la Ley $26.618,{ }^{1}$ la cual reconoció la institución del matrimonio a las parejas del mismo sexo. Esta ley puso sobre el escenario prácticas que ya se venían realizando, como la inseminación de una mujer con material genético de un tercero, estando en pareja con otra persona del mismo sexo, o la gestación de una mujer para una pareja de hombres que desea tener un hijo.

El artículo 36 de dicha norma introdujo una reforma al inciso c) del artículo 36 de la ley $26.413^{2}$ de Registro del Estado Civil y Capacidad de las Personas. Éste se refiere al contenido del acta de inscripción de los hijos nacidos dentro de un matrimonio. El texto expresa: "La inscripción deberá contener: [...] El nombre y apellido del padre y de la madre o, en el caso de hijos de matrimonios

\footnotetext{
1 Ley de matrimonio igualitario, 2010. Disponible en: http://www.psi.uba.ar/academica/carrerasdegrado/psicologia/ sitios_catedras/electivas/816_rol_psicologo/material/unidad2/complementaria/ley_de_matrimonio_igualitario.pdf ${ }_{2}^{2}$ Ministerio de Justicia y Derechos Humanos, Ley 26.413. Disponible en: http://servicios.infoleg.gob.ar/infoleglnternet/ anexos/145000-149999/145 345/texact.htm
} 
entre personas del mismo sexo, el nombre y apellido de la madre y su cónyuge, y tipo y número de los respectivos documentos de identidad". Si bien la ley no introdujo una modificación expresa al articulado del Código Civil -vigente en ese entonces- en materia de determinación de la filiación paterna matrimonial (artículo 243) o, en la determinación materna (artículo 242), el legislador algo ha dicho al respecto a modificar el modo de inscripción de los hijos en el Registro de Estado Civil y Capacidad de las Personas, y a disponer que cuando se trata de un matrimonio del mismo sexo se debe consignar en el acta el nombre de la madre y su cónyuge.

A partir de ello, se fueron suscitando algunos conflictos jurídicos en relación con la filiación de los niños nacidos por reproducción asistida. Estos dieron lugar a diferentes resoluciones judiciales que se constituyeron en antecedentes de la regulación hoy vigente.

Es el caso ${ }^{3}$ de una pareja de mujeres que solicitó una medida cautelar autosatisfactiva en representación de su hijo, con el objeto de que se dejara sin efecto el acto administrativo del Registro Civil de las Personas de la Ciudad Autónoma de Buenos Aires que denegaba el reconocimiento del niño por parte de una las actoras. El niño había nacido por un tratamiento de fertilización in vitro. El óvulo fecundado (con semen de donante) había sido aportado por la actora a la que se le impedía el reconocimiento -con quien tiene vínculo genético- y luego transferido a la mujer que lo dio a luz, cuyo vínculo había sido establecido. Solicitaron que se inscribiera el reconocimiento en la partida de nacimiento correspondiente, lo cual fue concedido por el tribunal de grado. ${ }^{4}$

Otro antecedente jurisprudencial ${ }^{5}$ ha sido el que dio lugar a la acción de amparo intentada por una pareja de mujeres del mismo sexo que tuvieron un hijo a través de las TRHA. Fueron contra la disposición del Registro de Estado Civil y Capacidad de las Personas que les denegó el pedido de inscripción del reconocimiento del niño por una de las accionantes. Pretendían que ambas mujeres fueran inscritas en la partida de nacimiento como madres del niño.

\footnotetext{
3 "'M.P.C. y otra c/GCBA s/medida cautelar' - Juzgado en lo Contencioso Administrativo y Tributario de la Ciudad Autónoma de Buenos Aires No. 4 - 07/04/2011", El Dial. Disponible en: http://www.eldial.com/nuevo/lite-jurisprudencia-detalle.asp?base $=14$ \&th $=$ u\&tid $=28303$

${ }^{4}$ Los argumentos en los que se fundó dicha resolución son el derecho a la igualdad y a no ser discriminado (en relación con la pareja), el derecho a la identidad del niño, a la autonomía personal y a la dignidad. Entendió el sentenciante que "La voluntad procreacional modifica la idea de identidad como sinónimo de vínculo biológico y, en cambio, inspira el contenido del derecho a la identidad en sentido amplio y multifáctico, inclusivo de aspectos que se vinculan con lo que se conoce como la identidad en sentido dinámico".

5 "'V. A. F. y otros vs. Gobierno de la Ciudad Autónoma de Buenos Aires s. Amparo' - Juzgado en lo Contencioso Administrativo y Tributario № 15 de la Ciudad Autónoma de Buenos Aires - 24/06/2011", Rubinzal.
} 
En subsidio, plantearon la inconstitucionalidad de los artículos 240 y 250 del Código Civil y 45 de la Ley 26413, por contravenir el derecho a la igualdad y la protección integral de la familia.

El niño nació en el año 2005. Ambas mujeres consintieron el tratamiento médico que dio lugar a ello. Posteriormente (2010), contrajeron matrimonio, con la expectativa de proteger su vínculo de familia y creyendo que así, quien no tenía vínculo jurídico con su hijo iba a poder reconocerlo legalmente. Esto les fue denegado por el registro y finalmente subsanado por resolución judicial.

Por último, otro planteo ${ }^{6}$ fue realizado por una mujer unida en matrimonio con otra, quien concibió un hijo mediante una técnica de fertilización asistida con semen de un donante anónimo. Luego de dar a luz, asistió al Registro Civil con su cónyuge para inscribir el nacimiento. Solicitaron que se asentara el reconocimiento del menor por parte de esta última. Dado que se rechazó la petición, promovieron acción de amparo, a fin que se dejara sin efecto la decisión denegatoria. El juez de grado hizo lugar a la petición con fundamento en el derecho del niño a la identidad y a ser oído; el derecho a la igualdad y no discriminación (en relación con la pareja), en la voluntad procreacional como factor determinante en la filiación de parejas del mismo sexo que recurren a TRHA, sumado al hecho de que lo que se pretendía no era el desplazamiento de la filiación materna establecida sino su complementariedad. ${ }^{7}$

Todos estos antecedentes evidenciaron la necesidad de contar con una regulación que diera respuesta a estos casos y, por tanto, que la regulación en materia de filiación fuera modificada. El 5 de junio de 2013 se sancionó la Ley 26.862 de acceso integral a los procedimientos y técnicas médico-asistenciales de reproducción médicamente asistida, ${ }^{8}$ que se centra en la cuestión de la cobertura médica de los tratamientos y los beneficiarios de la misma, más no modifica el régimen filiatorio argentino, que se encontraba regulado en el Código Civil entonces vigente.

\footnotetext{
6 "'M. Y. M. y otros c. GCBA s/amparo' - Juzgado en lo Contencioso administrativo y Tributario No. 6 de la Ciudad Autónoma de Buenos Aires - 12/07/2011", La Ley, 2011-D.

${ }^{7}$ Sostuvo el sentenciante "que si la ley prevé que los hijos de parejas del mismo sexo nacidos dentro del matrimonio serán matrimoniales y en consecuencia estarán reconocidos por ambos padres; si, la celebración del matrimonio no debe ser previa al nacimiento para que los hijos de los cónyuges obtengan tal carácter; si a su vez la ley veda establecer diferencias entre las filiaciones matrimoniales y extramatrimoniales y debe primar por mandato constitucional y legal local el interés superior del niño, debemos concluir que la interpretación dada a la ley por el Director del Registro Civil es discriminatoria y contraria a lo que ordenamiento dispone".

${ }^{8}$ Dicha norma ha sido reglamentada por el Decreto 956/2013, emitido el 19 de Julio de 2013. Disponible en www. infoleg.gob.ar
} 
Asimismo, se destaca la expresa mención de la norma al consentimiento médico previo e informado para la realización de los procedimientos, que denota la importancia de la voluntad para las TRHA. En su artículo 7 establece:

Tiene derecho a acceder a los procedimientos y técnicas de reproducción médicamente asistida, toda persona mayor de edad que, de plena conformidad con lo previsto en la ley 26.529, de derechos del paciente en su relación con los profesionales e instituciones de la salud, haya explicitado su consentimiento informado. El consentimiento es revocable hasta antes de producirse la implantación del embrión en la mujer. ${ }^{9}$

Por otro lado, dispone expresamente la prohibición de establecer requisitos o limitaciones que impliquen la exclusión de la cobertura de los tratamientos a cualquier destinatario en función de su orientación sexual o estado civil (artículo 8). La importancia de ello radica en que la norma ha sido sancionada con posterioridad a la ley de matrimonio igualitario. Por tanto, en total consonancia con la misma, resulta comprensiva de los diferentes tipos de familias posibles.

Todos estos antecedentes fueron considerados por los redactores del Código Civil y Comercial de la Nación para la regulación de la filiación derivada de las TRHA.

\section{Técnicas de reproducción humana asistida y voluntad procreacional}

El Código Civil y Comercial de la Nación ${ }^{10}$ ha regulado una tercera fuente filial, derivada del uso de las técnicas de reproducción humana asistida, en forma específica y autónoma de las ya conocidas filiación por naturaleza y por adopción, en atención a las propias particularidades y características que detenta el uso de estas técnicas (sobre todo en los supuestos de las técnicas heterólogas, es decir, con el aporte genético de un donante) y que repercuten directamente, en el campo filial. Básicamente, la legislación argentina regula diferente lo que es distinto.

\footnotetext{
${ }^{9}$ Por su parte, el artículo 7 del decreto reglamentario agrega que "El consentimiento informado deberá ser prestado por la persona que requiera la aplicación de técnicas de reproducción médicamente asistida, antes del inicio de cada una de ellas. El consentimiento informado y su revocación deben documentarse en la historia clínica con la firma del titular del derecho expresando su manifestación de voluntad. Se aplican, en lo pertinente, las Leyes № 26.529 de Derechos del Paciente en su relación con los Profesionales e Instituciones de la Salud y № 25.326 de Protección de los Datos Personales. En los casos de técnicas de reproducción médicamente asistida de baja complejidad el consentimiento es revocable en cualquier momento del tratamiento, o hasta antes del inicio de la inseminación. En los casos de técnicas de reproducción médicamente asistida de alta complejidad, el consentimiento es revocable hasta antes de la implantación del embrión".

${ }^{10}$ Aprobado por la Ley 26.994, Boletín Oficial, 8 de octubre, 2014. [Consulta: 22 de diciembre, 2016]. Disponible en: http://servicios.infoleg.gob.ar/infoleglnternet/verNorma.do?id=235975
} 
Natalia de la Torre sostiene:

Las TRHA nos colocan en un escenario distinto al producido en la filiación natural o adoptiva -sin perder de vista que existen lazos o características compartidos en las tres fuentes filiales- [...] En primer lugar, cabe destacar que el régimen en materia de filiación tiene por presupuesto ineludible, la existencia de una relación sexual entre dos personas de distinto sexo. Por el contrario, las prácticas de reproducción humana asistida carecen de este elemento, la inmediatez de la relación sexual está ausente en las TRHA [...] En segundo lugar, las TRHA permiten criopreservar embriones y/o material genético de las parejas o de las personas por tiempos prolongados, lo que nos lleva a una realidad: la posibilidad de que los deseos de paternidad/maternidad y las situaciones de las parejas cambien entre el inicio de un tratamiento y el fin [...] Por último, las TRHA hacen posible la disociación entre el elemento biológico, el genético y el volitivo, cobrando éste último primacía [...] Todos estos interrogantes reflejan las particularidades y especificidades que implica el uso de las TRHA, no pudiendo ser aprehendidas por las reglas de la filiación natural, ni por las reglas de la filiación adoptiva, volviéndose imperante la regulación diferencial y autónoma. ${ }^{11}$

De este modo, el artículo 558 del Código Civil y Comercial dispone:

La filiación puede tener lugar por naturaleza, mediante técnicas de reproducción humana asistida, o por adopción. La filiación por adopción plena, por naturaleza o por técnicas de reproducción humana asistida, matrimonial y extramatrimonial, surten los mismos efectos, conforme a las disposiciones de este Código. Ninguna persona puede tener más de dos vínculos filiales, cualquiera sea la naturaleza de la filiación.

En este sentido, la normativa argentina ha plasmado diferentes principios constitucionales-convencionales (artículos 1 y 2 del Código Civil y Comercial). Son los que sostienen y fundamentan la razón por la cual el Código Civil y Comercial amplía la regulación del derecho filial incorporando; de manera especial, qué acontece con la filiación cuando deriva del uso de las TRHA y el modo

\footnotetext{
"De La Torre, Natala, "Las técnicas de reproducción humana asistida: una tercera causa fuente filial", Rubinzal Culzoni.
} 
en que se hace, respetado y garantizando, por ejemplo y entre otros: a) el principio del interés superior del niño (artículo 3 de la Convención sobre los Derechos del Niño y artículo 3 de la ley 26.061); b) el principio de igualdad de todos los hijos, matrimoniales como extramatrimoniales; $c$ ) el derecho a la identidad y, en consecuencia, a la inmediata inscripción (artículos 7 y 8 de la Convención sobre los Derechos del Niño y artículo 11 de la ley 26.061); $d$ ) la mayor facilidad y celeridad en la determinación legal de la filiación; e) el acceso a la información de los niños nacidos de fertilización heteróloga; f) el derecho a gozar de los beneficios del progreso científico y su aplicación y $g$ ) el derecho a fundar una familia y a no ser discriminado en el acceso a ella.

Ahora bien, el elemento central sobre el que se construye la determinación de la filiación de los nacidos mediante el empleo de estas técnicas es la voluntad procreacional, debidamente plasmada en el consentimiento previo, informado y libre.

Kemelmajer de Carlucci y otras autoras ${ }^{12}$ afirman que si bien las TRHA son generalmente utilizadas por quienes no quieren renunciar a tener un hijo "genéticamente propio", el elemento genético no es el que determina la filiación, sino el volitivo: la voluntad procreacional. Ésta es la decisión, la voluntad de querer llevar adelante un proyecto parental, conjuntamente con otra persona, o bien, en el marco de una familia monoparental.

En este mismo sentido se manifiesta un sector de la doctrina nacional, el cual se posiciona a favor de esta regulación de las TRHA como una fuente de filiación autónoma. Para ellos, en ésta prevalece la voluntad procreacional como elemento determinante, independientemente de quién haya aportado los gametos. Lo hace con fundamento en los principios de la filiación enunciados anteriormente, en el principio de realidad, en el reconocimiento de la noción de socioafectividad y en el derecho a procrear como un aspecto trascendental del derecho humano a la salud sexual y reproductiva.

Por su parte, hay otros autores que señalan lo contrario. Consideran que las TRHA no debieran regularse como fuente de filiación diferente y que la mera

\footnotetext{
12 Kemelmajer de Carlucci, Herrera y lloveras, "Tratado de derecho de familia", según el Código Civil y Comercial 2014, tomo II, Argentina, Rubinzal - Culzoni.

Díaz de Guijarro afirmaba que la procreación se encuentra integrada por tres aspectos diferenciados: a) la voluntad de la unión sexual; b) la voluntad procreacional y c) la responsabilidad procreacional. Respecto a la segunda, entendida como el deseo o intención de crear una nueva vida, derecho que también merece la protección del ordenamiento jurídico al tutelarse a la persona en su decisión libre de tener un hijo. Como consecuencia de aquella, la responsabilidad procreacional deriva del hecho de la procreación, que es la responsabilidad directa de los progenitores respecto a la persona por nacer. Diaz dE GUIJARRo, ENRIQUE, "La Voluntad y la responsabilidad procreacionales como fundamento de la determinación jurídica de la filiación", Revista de Jurisprudencia Argentina La Ley, 1965.
} 
voluntad de procrear de las personas no puede ser el factor determinante de una filiación. Sostienen que las TRHA son contrarias a la naturaleza de las cosas, y por tanto no son valiosas para la sociedad; constituyen una alteración del sistema de parentesco y filiación (porque contradicen el principio de verdad biológica) y rompen con la idea tradicional de familia. Además, afirman que producen discriminación de los hijos en virtud de la forma en que vienen al mundo, y atentan contra su derecho a la identidad e interés superior (toda vez que vienen a satisfacer el deseo de los adultos) a partir de una mirada adultocéntrica.

Independientemente de dichas posiciones doctrinarias, el debate ha sido zanjado a partir de la reciente sanción y vigencia del Código Civil y Comercial de la Nación, que (aunque en este aspecto sigue siendo duramente cuestionado) resolvió la cuestión normativa en el sentido que veremos a continuación.

\section{La regulación}

El artículo 562 del propio Código Civil y Comercial, al definir voluntad procreacional, reafirma que los nacidos por las TRHA son hijos de quien dio a luz y del hombre o de la mujer que prestó su consentimiento, siempre que éste se encuentre debidamente inscripto en el Registro Civil, con independencia de quién haya aportado los gametos.

Esta norma se ve complementada con los artículos 560 y 561, el cual disponen los requisitos y la forma en que deberá cumplimentarse la instrumentación del consentimiento informado. Previene que el mismo habrá de ser recabado por el Centro de Salud interviniente. Aquellas personas que accedan al uso de las TRHA deben renovar su consentimiento cada vez que se procede a la utilización de gametos o embriones. Es decir, el consentimiento tiene que ser actual y contemporáneo; debe actualizarse en cada procedimiento.

En cuanto a la instrumentación de dicho documento, a los efectos de la inscripción ante el Registro del Estado Civil y Capacidad de las Personas de los niños nacidos mediante el empleo de este tipo de procedimientos médicos, se dispone que deberá contener los requisitos previstos en las disposiciones especiales al efecto, para su posterior protocolización ante escribano público o certificación ante la autoridad sanitaria correspondiente a la jurisdicción (el Ministerio de Salud sería la autoridad de aplicación encargada de organizar el procedimiento de certificación ante dicho organismo).

El consentimiento es libremente revocable conforme lo dispone el artículo 561 del Código Civil y Comercial, mientras no se haya producido la concepción en la persona o la implantación del embrión, en concordancia con lo dispuesto en el artículo 7 de la Ley 26.862 de Acceso Integral a los Procedimientos 
y Técnicas Médico Asistenciales de Reproducción Medicamente Asistida y su Decreto Reglamentario N 956/2013.

Ahora bien, es dable señalar que cuando en el proceso reproductivo se utilicen gametos de terceros, no se genera vínculo jurídico alguno respecto a los nacidos mediante el uso de las TRHA, excepto a los fines de los impedimentos matrimoniales en los mismos términos que la adopción plena (artículo 575 del Código Civil y Comercial). Tampoco será admisible el reconocimiento ni el ejercicio de acción de filiación o de reclamo alguno de vínculo filial entre éste y el nacido por el uso de estos tratamientos.

La legislación civil y comercial, en los artículos 563 y 564, se ocupa del derecho a la información de las personas nacidas por TRHA. Reconoce la particularidad que ostenta el derecho a la identidad en las TRHA heterólogas. De esta manera, dispone que la información relativa a que la persona ha nacido por el uso de técnicas de reproducción humana asistida con gametos de un tercero debe constar en el correspondiente legajo base para la inscripción del nacimiento. A petición de aquellas, podrá: a) obtenerse del centro de salud interviniente información relativa a datos médicos del donante, cuando es relevante para la salud; $b$ ) revelarse la identidad del donante, por razones debidamente fundadas, evaluadas por la autoridad judicial por el procedimiento más breve que prevea la ley local.

En este sentido, el Código Civil y Comercial ha optado por un sistema de anonimato relativo, también denominado anonimato intermedio y equilibrado, de conformidad con todos los intereses en juego. Toma en cuenta que, de este modo, se garantiza: la necesidad de que haya donantes; el derecho a gozar de los beneficios del progreso científico de quienes acceden a los tratamientos heterólogos; $y$ el derecho del niño nacido por TRHA a conocer su origen genético.

De acuerdo con los alcances del citado artículo 564, respecto al derecho de los niños a conocer su información genética, se diferencian claramente dos aspectos: información no identificatoria (datos genéticos o de salud sobre el donante); e información identificatoria (nombre, apellido y datos que permiten individualizar al donante), que sólo podrá ser revelada mediante autorización judicial previa.

En cuanto a las formas de determinación, el artículo 569 establece que la filiación matrimonial queda determinada legalmente. Ésta se prueba: por la inscripción del nacimiento en el Registro del Estado Civil y Capacidad de las Personas y por la prueba del matrimonio; por sentencia firme en juicio de filiación; en los supuestos de técnicas de reproducción humana asistida, por el consentimiento previo, informado y libre debidamente inscrito en el Registro 
del Estado Civil y Capacidad de las Personas. Este último inciso sigue la misma lógica que el artículo 570 del Código Civil y Comercial que, en referencia a la determinación de la filiación extramatrimonial, establece que este tipo de filiación queda determinada por el reconocimiento, por el consentimiento previo, informado y libre al uso de las técnicas de reproducción humana asistida, o por la sentencia en juicio de filiación que la declare tal.

En otras palabras, en todos los casos en que se recurre a las TRHA para la ley argentina, ya sea una persona sola, casada o en unión convivencial, del mismo o distinto sexo, sean técnicas homólogas o heterólogas, la filiación se determina por la voluntad expresada a través de los consentimientos legales, con independencia de quién haya aportado los gametos.

La suscripción de este documento reviste tal importancia, que blinda la posibilidad de impugnar la filiación (matrimonial o extramatrimonial) de los hijos nacidos mediante el uso de estos tratamientos, cuando haya mediado de conformidad con las disposiciones del Código y las que se establezcan mediante una ley especial, con independencia de quién haya aportado los gametos (artículo 577 del Código Civil y Comercial). Es decir, no es posible impugnar la filiación de quien ha prestado el correspondiente consentimiento en los términos que instruye el Código Civil y Comercial.

Del mismo modo, el artículo 588, tercer párrafo, prevé que en los supuestos de filiación por técnicas de reproducción humana asistida la falta de vínculo genético no puede invocarse para impugnar la maternidad, si ha mediado consentimiento previo, informado y libre. Lo mismo ocurre con la impugnación del reconocimiento.

Por último, es necesario advertir que el mismo Código Civil y Comercial se ocupó de la situación de los niños nacidos mediante el uso de las TRHA antes de su puesta en vigencia. Dispone una cláusula transitoria donde prevé que éstos son hijos de quien dio a luz y del hombre o la mujer que también ha prestado su consentimiento previo, informado y libre a la realización de la técnica que dio origen al nacido. Por tanto, se debe completar el acta de nacimiento ante el Registro Civil y Capacidad de las Personas cuando sólo constara vínculo filial con quien dio a luz y siempre con el consentimiento de la otra madre o del padre que no figura en dicha acta, según consta en el capítulo 2 del título $\mathrm{V}$ del libro segundo del Código Civil y Comercial. 


\section{Desafíos}

A partir de esta regulación y a poco más de un año de la entrada en vigor del Código Civil y Comercial, una vez más la realidad nos ha mostrado la complejidad del tema. Han tenido lugar avances así como tensiones que nos enmarcan en nuevos desafíos y posibilidades. Desde esta perspectiva, nos proponemos visibilizar y reflexionar acerca de algunos de estos cruces entre derecho y realidad. Nuestro eje será la voluntad procreacional y su instrumentación a través del consentimiento informado, en tanto elemento central para la determinación de la filiación por TRHA. Analicemos estos cruces.

Un primer aspecto importante que se planteó judicialmente a los días de la entrada en vigencia del nuevo Código, es la determinación de la filiación por TRHA en relación con la aplicación de la ley en el tiempo, es decir, el caso de niñas y niños que habían nacido o sido concebidos por reproducción asistida con anterioridad a la nueva legislación.

El caso fue dirimido el 13 de agosto de 2015 por el Juzgado Nacional de primera Instancia en lo Civil núm. 8, en los autos caratulados "C., G. J. s/ información sumaria”. ${ }^{13}$ Se declara el emplazamiento del estado de hijo de un niño concebido por TRHA respecto a su progenitor, quien había prestado su consentimiento previo, libre e informado y falleció meses después de su nacimiento, cuando aún no lo había reconocido legalmente. De acuerdo con la prueba producida en la causa, se entendió que el consentimiento había sido prestado de conformidad con los artículos 560 y 561 del nuevo Código. Se ordenó que se agregara a la partida de nacimiento el apellido del padre.

Esta decisión se fundó, principalmente, en la aplicación del artículo 9 cláusula tercera de la ley 26.994, que. Como excepción al principio de irretroactividad de la ley que prevé el artículo $7,{ }^{14}$ dispone que las personas nacidas por TRHA antes de la entrada en vigencia del nuevo Código son hijos/as de

\footnotetext{
13 "Aplican el nuevo CCyC al ordenar la inscripción del nacimiento de un niño concebido mediante técnicas ICSI", SAIJ. [Consulta: 25 de septiembre, 2016]. Disponible en: http://www.infojus.gob.ar/aplican-nuevo-ccyc-al-ordenar-inscripcion-nacimiento-nino-concebido-mediante-tecnicas-icsi-nv12407-2015-08-13/123456789-0abc-704-21tiIpssedadevon?utm_source=Facebook\&utm_medium=Social\&utm_campaign=Jurisprudencia

Véase Vázouez Acatto, Mariana, "Se hace camino al andar, el Código Civil y Comercial y la primera sentencia sobre técnicas de reproducción humana asistida", Revista de Derecho de Familia, vol. 1, No. 50, 2016.

${ }^{14}$ Artículo 7 del Código Civil y Comercial. Eficacia temporal. "A partir de su entrada en vigencia, las leyes se aplican a las consecuencias de las relaciones y situaciones jurídicas existentes.

La leyes no tienen efecto retroactivo, sean o no de orden público, excepto disposición en contrario. La retroactividad establecida por la ley no puede afectar derechos amparados por garantías constitucionales.

Las nuevas leyes supletorias no son aplicables a los contratos en curso de ejecución, con excepción de las normas más favorables al consumidor en las relaciones de consumo."
} 
quien dio a luz y del hombre o la mujer que prestó su consentimiento previo, informado y libre a la realización del procedimiento que dio origen a la persona nacida. Por tanto, se debe completar el acta de nacimiento ante el Registro Civil y Capacidad de las Personas cuando sólo consta vínculo filial con quien dio a luz y siempre con el consentimiento de la otra madre o del padre que no figura en dicha acta. El fallo se refirió también, entre otras disposiciones relativas a la determinación de la filiación, al artículo 577. Hizo primar el elemento volitivo (voluntad procreacional) plasmado en el correspondiente instrumento (consentimiento informado) como causa fuente de la filiación, conforme lo establece la actual regulación.

Otro caso que tomó conocimiento público y se resolvió en sede administrativa, por lo cual no fue necesaria su judicialización, fue el de una niña nacida en Córdoba mediante TRHA. Sus dos progenitoras encontraron trabas para la inscripción del nacimiento en virtud de una errada interpretación del nuevo Código por parte del Registro Civil municipal. Este último entendió que por aplicación del artículo 561 la voluntad debía "ser ratificada o protocolizada para la inscripción” y "porque el tratamiento inicial fue antes de la vigencia del nuevo Código".

$\mathrm{Al}$ analizar el caso, Marisa Herrera desestimó este argumento, ya que el nuevo Código en ningún momento requiere de una "ratificación" del consentimiento prestado; sólo se exige la protocolización. Asimismo, por aplicación de la mencionada cláusula tercera del artículo 9 de la ley 26.994, en nada obsta que el consentimiento haya sido prestado con anterioridad a la entrada en vigencia del nuevo Código. Esta disposición establece que se proceda a la inscripción pertinente sin agregar requisitos, sobre la base de la consideración primordial del interés superior del niño. De no procederse a su inmediata inscripción, se estarían vulnerando sus derechos humanos. ${ }^{15}$ Finalmente, la cuestión se resolvió en sede administrativa. Previa protocolización del consentimiento prestado, la niña obtuvo su partida de nacimiento. ${ }^{16}$

Por otra parte, en la provincia de Buenos Aires, la directora del Registro de las Personas ordenó el 27 de abril de 2016, por disposición 660/16, que los progenitores/as que deseen agregar el apellido del otro progenitor/a, respecto

\footnotetext{
15 "Duras críticas al Registro Civil por no inscribir a una niña", La Voz, 25 de octubre, 2015. [Consulta: 25 de septiembre, 2016]. Disponible en: http://www.lavoz.com.ar/ciudadanos/duras-criticas-al-registro-civil-por-no-inscribir-una-nina

16 "Guillermina Francesca ya tiene su partida de nacimiento", Día a Día, 20 de octubre, 2015. [Consulta: 25 de septiembre, 2016]. Disponible en: http://www.diaadia.com.ar/cordoba/guillermina-francesca-ya-tiene-su-partida-de-nacimiento
} 
a los nacidos por TRHA antes de la entrada en vigencia del nuevo Código, deben manifestar, expresamente y por escrito, el consentimiento acerca de su voluntad procreacional a los fines de completar el acta de nacimiento ante el Registro Civil y Capacidad de las Personas, cuando sólo constara vínculo filial de quién dio a luz (artículo 1). Como anexo a dicha norma, se aprobó un modelo de "Declaración de Consentimiento" a los fines de su implementación.

Otra cuestión por considerar son los aspectos de fondo y forma que debe reunir este consentimiento para producir plenos efectos jurídicos. Doctrinariamente, se ha entendido que los requisitos del consentimiento para ser jurídicamente válido son: $a$ ) personal; $b$ ) informado; c) actual; $d$ ) manifiesto y expreso; e) libre; f) gratuito; $g$ ) solicitado o requerido; $h$ ) recepticio; $i)$ específico; $j$ ) obligatorio; $k$ ) revocable. ${ }^{17}$

Como vimos, el Código Civil y Comercial sienta las bases en la materia a través de los artículos 560 y 561. Estos aportan los lineamientos o reglas generales en materia filiatoria por TRHA. Entre ellos podemos destacar cuatro aspectos. El centro de salud interviniente está obligado a recabar el consentimiento de las personas que se someten a las técnicas. El consentimiento debe ser previo, informado y libre. La instrumentación del consentimiento se difiere a disposiciones especiales. Es obligada su protocolización ante escribano público o certificación ante la autoridad sanitaria correspondiente a la jurisdicción.

En cuanto a los aspectos formales, podemos destacar tres reglas fundamentales: el requisito de instrumentación, la remisión a leyes especiales y la posterior protocolización o certificación. Con respecto a la primera cuestión, la regla de instrumentación marca una clara pauta formal: el consentimiento debe ser escrito. Esto resulta de toda armonía y coherencia con dos leyes especiales en la materia: la ley de acceso integral a las TRHA 26.862 con su decreto reglamentario 956/2013 (artículo 7) y la ley de derechos del paciente 26.529 (artículo 7).

Sobre la remisión a disposiciones especiales, entendemos que la lógica de dicha derivación radica en la propia finalidad del Código que, como cuerpo normativo que se sanciona con perspectivas de estabilidad duradera, fija principios y reglas en materia filiatoria sin dejar de articular con el resto del ordenamiento jurídico como un todo. Con ello permite la dinámica necesaria para la implementación de los derechos como la instrumentación del consentimiento. Entre estas leyes especiales debemos considerar a las dos mencionadas

\footnotetext{
17 Lamm, Eleonora, Rodriguez iturburu, Mariana y Rubaja, Nieve, "Tecnicas de reproduccion humana asistida", en Aida Kemelmajer de Carlucci, Marisa Herrera y Nora Lloveras (dirs.), Tratado de Derecho de Familia, tomo V-A, Santa Fe, Rubinzal - Culzoni, 2016.
} 
anteriormente (ley de acceso integral y ley de derechos del paciente) y las que en un futuro se dicten en relación con la materia, ${ }^{18}$ así como las normativas sobre inscripción y registro de nacimientos.

En consecuencia, esta técnica legislativa permite, por un lado, compatibilizar con los sistemas registrales jurisdiccionales; por otro, impone zanjar efectivamente esta cuestión, puesto que la falta de disposiciones regulatorias en materia formal no puede impedir el ejercicio de un derecho reconocido. ${ }^{19} \mathrm{En}$ este sentido, y dada la conformación federal del sistema de gobierno de nuestro país, cabe mencionar que distintas jurisdicciones provinciales han emitido normativas para adecuar el sistema registral a las particularidades de las inscripciones de nacimiento por TRHA, como ha ocurrido con Chaco, ${ }^{20}$ Córdoba $^{21} \mathrm{y}$ Mendoza. ${ }^{22} \mathrm{~A}$ continuación, y junto al análisis del siguiente aspecto, haremos mención a una disposición registral dictada en la provincia de Buenos Aires, donde se han establecido algunos requisitos formales para dicha jurisdicción.

Por último, en cuanto al requisito de fe pública, el Código ofrece una doble vía: la protocolización por escribano o la certificación por autoridad sanitaria competente. Aquí es importante considerar que las distintas jurisdicciones locales deben garantizar efectivamente la segunda opción. De lo contrario, aquellas personas que no cuenten con los recursos económicos para costear la labor de un notario se verían vulneradas y discriminadas en el ejercicio de derechos fundamentales. Con ello se afectaría derechos filiatorios e identitarios de niños y niñas.

En este sentido, basándose en la ley nacional antidiscriminatoria 23.592, el 5 de mayo de 2016, la directora provincial del Registro de las Personas de la Provincia de Buenos Aires estableció, por disposición 1093/16, que el consentimiento podrá ser certificado al momento de la inscripción del nacimiento por TRHA en el propio registro civil, en cada delegación provincial. Así, ordenó que, en las inscripciones de nacimiento ocurridas a partir de la entrada en vigencia

\footnotetext{
${ }^{18}$ Actualmente se encuentra en tratamiento en la Cámara de Senadores de la Nación el proyecto de ley, con número de expediente 4058-D-2014 (con media sanción) de la ley especial de TRHA.

${ }^{19}$ Véase Herrera, Marisa y Pellegrini, María Victoria, "El rol de los registros civiles en las relaciones de familia. Impacto del nuevo Código", Revista La Ley, 2015.

${ }^{20}$ Decreto 208/2015. "Registro del Estado Civil y Capacidad de las Personas. Modificación de las actas de matrimonio", sAlJ. [Consulta: 22 de septiembre, 2016]. Disponible en: http://www.saij.gob.ar/registro-estado-civil-capacidad-personas-modificacion-actas-matrimonio-registro-estado-civil-capacidad-personas-modificacion-actas-matrimonio-nv12487-2015-06-01/123456789-0abc-784-21ti-Ipssedadevon

${ }^{21}$ Ministerio de Justicia y Derechos Humanos, Resolución 113/2015. [Consulta: 22 de septiembre, 2016]. Disponible en: http://boletinoficial.cba.gov.ar/wp-content/4p96humuzp/2015/12/161215_bocba_1stj9N19.pdf

22 Dirección del Registro Civil y Capacidad de las Personas, Manual para los oficiales públicos. [Consulta: 22 de septiembre, 2016]. Disponible en: http://www.jus.mendoza.gov.ar/documents/43978/172516/Nuevo+Codigo+Civil+-+Manual+para+los+oficiales+publicos.pdf/9b7fedb7-9dc8-4e40-9eef-931d729c2751
} 
del Código Civil y Comercial, el consentimiento exigido por el artículo 561 podrá ser presentado al momento de la inscripción del nacimiento para su certificación por parte del delegado. Este último otorgará fe pública al instrumento previa manifestación y ratificación ante su presencia, para su posterior archivo en calidad de documentación base de la inscripción (artículo 1).

Asimismo, en dicha disposición registral se requiere que en el acto de la registración se presente el instrumento donde conste el consentimiento, por escrito y en original, con el nombre de la institución sanitaria donde se haya realizado el tratamiento de fertilización, con la debida constancia de habilitación, nombre de los médicos intervinientes y datos de las personas que se someten a las TRHA y otorgan su consentimiento. Dicho documento debe estar suscrito por el médico, el responsable administrativo de la institución y los progenitores (artículo 2). Como podemos observar, en este supuesto se están detallando, a través de disposición especial, requisitos formales de instrumentación del consentimiento informado para su implementación y efectos en materia filial, tal como prescribe el Código Civil y Comercial.

Ahora pasemos a considerar los aspectos de fondo, es decir, aquellos vinculados con el contenido mínimo que debe reunir el consentimiento. El artículo 560 nos habla del consentimiento "informado". Este adjetivo es central para entender cuál debe ser su contenido y por qué.

Desde un análisis intrasistémico del artículo 59, que regula dentro de los derechos y actos personalísimos el consentimiento informado para los actos médicos e investigaciones en salud (parte general del Código), ofrece lineamientos fundamentales al definirlo como:

la declaración de voluntad expresada por el paciente, emitida luego de recibir información clara, precisa y adecuada, respecto a: a) su estado de salud; b) el procedimiento propuesto, con especificación de los objetivos perseguidos; c) los beneficios esperados del procedimiento; d) los riesgos, molestias y efectos adversos previsibles; e) la especificación de los procedimientos alternativos y sus riesgos, beneficios y perjuicios en relación con el procedimiento propuesto; f) las consecuencias previsibles de la no realización del procedimiento propuesto o de los alternativos especificados.

Desde una visión extra sistémica, la ley 26.529 de derechos del paciente también define el consentimiento informado en términos similares, a través de su artículo 5. El consentimiento informado implica un deber previo de los pro- 
fesionales intervinientes: el deber de informar. Esta información debe reunir ciertos requisitos: completitud, adecuación, claridad y precisión. Esto se funda en que contar con información es imprescindible para garantizar el respeto del principio bioético de autonomía. Los pacientes deben contar con todos los datos para elegir libre y plenamente si someterse o no al tratamiento y a sus consecuencias. En este sentido, y dada la asimetría en el vínculo profesional-paciente, ninguna información debe presumirse como conocida y debe ser brindada en forma comprensible.

Otro aspecto fundamental y específico para este tipo de actos es la información relativa a la fertilización heteróloga (aquella que implica la utilización de material genético de un tercer donante). Los consentimientos informados deben contener toda la información hábil para que los usuarios de estas técnicas conozcan sus derechos y, en especial, los derechos del hijo/a que eventualmente nazca. ${ }^{23}$ En las últimas Jornadas Nacionales de Derecho Civil (2015) ( las primeras luego de la sanción del Código Civil y Comercial de la Nación), que tuvieron lugar en la ciudad de Bahía Blanca, provincia de Buenos Aires, se decidió doctrinariamente por unanimidad que "Los consentimientos informados a las TRHA heterólogas, que deben constar en el correspondiente legajo base para la inscripción del nacimiento (art. $563 \mathrm{CCyCN}$ ) deben ser proporcionados por los propios progenitores en ejercicio de su responsabilidad parental al Registro Civil”. ${ }^{24}$

Es importante considerar que el consentimiento informado en los casos de TRHA tiene una doble finalidad jurídica: como fuente de filiación y como acto personalísimo en relación con el derecho a la salud y cuidado del cuerpo. En la Argentina, el proceso de adecuación de estos consentimientos a las pautas mencionadas ha sido progresivo en el tiempo. Varios centros de salud han venido trabajando hace años, incluso han empezado a hacerlo en paralelo al debate y sanción del Código con la Sociedad Argentina de Medicina Reproductiva (Samer). A tal punto, se creó la Comisión Asesora de Técnicas de Reproducción Humana Asistida (CATRHA), de conformación interdisciplinaria. ${ }^{25}$ Es 100 este ámbito, y como resultado de este trabajo conjunto, se elaboraron modelos

\footnotetext{
${ }^{23}$ Cfr. Herrera, MarisA, "¿Cómo es la inscripción de los niños nacidos de técnicas de reproducción asistida?". [Consulta: 22 de septiembre, 2016]. Disponible en: civil.com/wp-content/uploads/2016/04/2016-Inscripcion-de-nacimiento-reproduccio\%CC\%81n-asistida.pdf

${ }^{24}$ XXV Jornadas Nacionales de Derecho Civil, Bahía Blanca, 2015. [Consulta: 22 de septiembre, 2016]. Disponible en: http://jndcbahiablanca2015.com/wp-content/uploads/2015/10/CONCLUSIONES-06.pdf

${ }^{25}$ Herrera, Marisa, "¿Cómo es la inscripción de los niños nacidos de técnicas de reproducción asistida?". [Consulta: 22 de septiembre, 2016]. Disponible en: civil.com/wp-content/uploads/2016/04/2016-Inscripcion-de-nacimiento-reproduccio\%CC\%81n-asistida.pdf
} 
de consentimientos informados unificados a partir de la implementación del Código Civil y Comercial. Se contemplaron los distintos supuestos de tratamientos y sus especificidades, tanto de alta y baja complejidad como para técnicas homólogas y heterólogas. Estos modelos constituyen un insumo social y técnico superlativo para todos los centros de medicina reproductiva del país.

En el tratamiento parlamentario para la sanción del Código argentino, dos figuras quedaron fuera de la nueva regulación en relación con las TRHA (sin perjuicio de que habían sido incorporadas en el Anteproyecto). ${ }^{26}$ Se trata de la gestacion por sustitucion ${ }^{27}$ (GS) y la fertilización post mortem ${ }^{28}$ (FPM).

En la triple posibilidad en que el derecho se puede ubicar frente a estas figuras (regular, prohibir o silenciar), el ordenamiento jurídico argentino actualmente se encuentra en la última opción, pues se omitió todo tratamiento legislativo de las mismas. Este silencio implica incertidumbre e imprevisibilidad. Sus consecuencias ya se han hecho notar jurisprudencialmente, frente a la búsqueda de seguridad jurídica ante el Poder Judicial.

Por un lado, en materia de Gs, contamos a la fecha en la Argentina con catorce casos judiciales. Se puede observar que, sin perjuicio de las particularidades de cada supuesto y los distintos encuadres procesales, en todos los casos se ha dado lugar al emplazamiento filial a favor de los comitentes. Casi todos los procedimientos iniciaron después del nacimiento de los niños. Los comitentes efectuaron una presentación por la cual impugnaban la filiación materna de la gestante y solicitaban el emplazamiento del progenitor con quien el/los niño/s no se encontraban vinculados. En una oportunidad, pese a tener el certificado de nacimiento, la niña no había sido inscrita aún, por lo que se solicitó directamente la inscripción en favor de los comitentes.

\footnotetext{
${ }^{26}$ Redactado por la Comisión integrada por los doctores Ricardo Luis Lorenzetti, Elena Highton de Nolasco y Aída Kemelmajer de Carlucci, en cumplimiento del decreto presidencial 191/2011.

${ }^{27}$ La Organización Mundial de la salud define a la gestación por sustitución a través de la referencia a la "gestante subrogada", diciendo que es la "mujer que lleva adelante un embarazo habiendo acordado que ella entregará el bebé a los padres previstos. Los gametos pueden originarse de los padres previstos y/o de terceros". ZeGER-HocHSCHILD, FERnANDo, Glosario de terminología en técnicas de reproducción asistida, International Committee for Monitoring Assisted Reproductive Technology - Organización Mundial de la Salud, 2010. [Consulta: 21 de septiembre, 2016]. Disponible en: http://www.who.int/reproductivehealth/publications/infertility/art_terminology2/es/

${ }^{28}$ La fertilización post mortem es una técnica de reproducción humana asistida que se realiza después de la muerte de uno de los miembros de la pareja. Puede realizarse con un embrión criopreservado de la pareja, generado durante la vida de ambos, o bien, que el embrión sea generado también post mortem con material genético criopreservado del fallecido/a u obtenido a través de la extracción de su cadáver. Pérez, AgustinA, "Argumentos y contraargumentos en torno a la fertilización post mortem. ¿Qué tiene la maternidad/paternidad póstuma que incomoda tanto?", Revista de Derecho Privado y Comunitario, No. 2016-1, Rubinzal - Culzoni, 2016.
} 
Por otra parte, en dos casos se solicitó autorización judicial para la transferencia embrionaria y posterior inscripción a nombre de la comitente, es decir, con anterioridad a la realización del tratamiento y tal como se encontraba previsto en la norma proyectada (que fue eliminada del Código Civil y Comercial). Finalmente, la accionante solicitó, como medida precautoria, que el niño fuera inscrito a su nombre una vez nacido, dado que al momento la gestante se encontraba embarazada.

Como podemos observar, la falta de regulación implica que el tratamiento de la cuestión tome formas muy heterogéneas y, en última instancia, dependa deliberadamente del criterio del juzgado, lo cual deviene inaceptable en un Estado de derecho. En consecuencia, esta laguna legislativa afecta los derechos de los sujetos involucrados, así como las debidas garantías a los fines del consentimiento informado, el cual se realiza de hecho al margen de la legalidad y puede implicar vulnerabilidades, sobre todo en relación con quienes se encuentren fácticamente en una situación más “débil”.

En las mencionadas Jornadas Nacionales de Derecho Civil (2015), el tema de la Gs se abordó en el marco de la comisión 6 de Derecho de Familia. Por unanimidad, se concluyó que "aún sin ley, al no estar prohibida, se entiende que la gestación por sustitución está permitida”. A esto se agregó que "se debe regular la gestación por sustitución en una Ley Especial conforme el criterio del art. 562 del Anteproyecto del Código Civil y Comercial de la Nación” ${ }^{29}$ y que "la ley especial de gestación por sustitución debe hacer hincapié en la protección de todas las personas intervinientes". ${ }^{30}$

Por otro lado, respecto a la fecundación post mortem, se registran cinco casos judiciales en el país. En todos, sin perjuicio de sus diferencias fácticas, se ha autorizado la técnica. Esas diferencias fácticas son muy importantes en lo relativo al consentimiento del difunto, ya que en dos de estos casos se solicitó la extracción de gametos del cadáver (por lo cual no existía consentimiento previo de la persona fallecida). En los otros tres, el material genético (en dos casos gametos y en uno un embrión formado con su semen) se encontraba criopreservado, por lo que existía un consentimiento para ello.

\footnotetext{
${ }^{29}$ XXV Jornadas Nacionales de Derecho Civil, Bahía Blanca, 2015. [Consulta: 22 de septiembre, 2016]. Disponible en: http://jndcbahiablanca2015.com/wp-content/uploads/2015/10/CONCLUSIONES-06.pdf

El precepto referido del anteproyecto es el que regulaba la figura que luego fue eliminada. Recientemente se ha presentado en la Cámara de Diputados de la Nación dos proyectos de ley que tienen por objeto la regulación de la GS (proyecto 5700-D-2016 y proyecto 5759-D-2016).

${ }^{30}$ Esta fue la conclusión de la mayoria. Para la minoria, en este aspecto, "la ley especial de gestación por sustitución debe hacer hincapié en la protección de la persona gestante".
} 
En consecuencia, y ante la falta de reglas precisas que regulen la materia, observamos cómo los jueces han ido decidiendo. Esto implica que en algunos casos se omita el consentimiento informado, el cual constituye un acto personalísimo en esta materia, donde lo que se decide, además de la disposición del propio cuerpo, es la determinación de un proyecto filial, es decir, que falta la voluntad procreacional previa del fallecido.

En virtud de lo expuesto, puede concluirse preliminarmente y a los fines de este trabajo que el silenciar la regulación de estas figuras termina afectando derechos en materia de consentimiento informado. Esto se da por la ausencia de reglas claras y mecanismos de garantía, tanto para la determinación de la filiación como para el ejercicio de la autonomía frente al acto médico. ${ }^{31}$

Otro cruce muy importante que ha empezado a tener un abordaje doctrinario creciente de manera reciente es la responsabilidad civil y las TRHA. ${ }^{32} \mathrm{Al}$ respecto, en principio las obligaciones médicas ante el paciente serán de medios, ya que no se puede asegurar el resultado del tratamiento (es decir, el embarazo). Sin embargo, una de las excepciones, en consonancia con la evolución del derecho de daños, es la obligación de resultado que engendra el recabar el consentimiento informado y cumplir con el deber de información. Esto se encuentra fundamentado en los artículos 560, 561 y 59. Implica una responsabilidad de tipo objetiva (según el artículo 1768) ${ }^{33}$ para los profesionales y centros de salud.

Por su parte, el artículo 1720, en materia de responsabilidad civil, establece que el consentimiento libre e informado del damnificado, en la medida en que no constituya una cláusula abusiva, libera de la responsabilidad por los daños derivados de la lesión de bienes disponibles. Por ende, si "el médico actúa sin obtener debidamente la voluntad previamente informada del paciente, asume unilateralmente los riesgos propios de su intervención al no haberse desarrollado adecuadamente la información". ${ }^{34}$

De allí la importancia de que los profesionales y centros de salud cumplan adecuadamente estas obligaciones, que se fundamentan en el principio bioético de autonomía. De lo contrario, se pone de relieve el campo de la responsa-

\footnotetext{
${ }^{31}$ Véase De la Torre, Natala y Argerl, Gastón, "Los avances científicos en materia de trha y sus implicancias en el derecho de familia: diagnóstico genético preimplantatorio y filiación post mortem", en Silvia Eugenia Fernández (dir.), Tratado de derechos de niños, niñas y adolescentes, tomo I, pp. 1031.

32 Véase Herrera, Marisa y Salturi Amezcua, Martina, "Técnicas de reproducción humana asistida y responsabilidad civil", Revista La Ley, Buenos Aires, 2016.

${ }^{33}$ Este artículo establece que para las profesiones liberales la responsabilidad es subjetiva, excepto que se haya comprometido un resultado concreto.

${ }^{34}$ Cámara de Apelaciones en lo Civil y Comercial N¹, Sala 2, La Plata, Buenos Aires, "O'Keeffe, Cristina Mabel cl Hospital Prof. Dr. Adolfo Rossi s/ Daños y perjuicios", 23/09/2003, www.saij.gob.ar
} 
bilidad médica, que se activa tanto por aplicación del Código Civil y Comercial como de la normativa de protección de derechos del consumidor, sobre todo ante una actividad riesgosa. ${ }^{35}$

En Uruguay, esta responsabilidad fue aplicada judicialmente por el Juzgado Letrado de Primera Instancia en lo Civil de $3^{\circ}$ Turno de Montevideo, en el fallo del 22 de febrero de 2012 dictado en la causa Lemes Ferreyra, Mabel y otros vs. Asociación Española Primera de Socorros Mutuos. ${ }^{36}$ En esta se determinó que "el ilícito se configuró ante la falta de acreditación por parte de la accionada del cumplimiento de la obligación de recabar el consentimiento informado y del deber de informar los riesgos que existían en el proceso de crioconservación y descongelamiento de los embriones". ${ }^{37}$ De la decisión judicial se desprende, asimismo, que la obligación de recabar el consentimiento informado “encierra el deber de informar y que esta información debe ser dada por los médicos responsables del tratamiento, en forma absolutamente independiente a que los pacientes accedan o puedan acceder a otro tipo de información". ${ }^{38}$

Por último, vamos a considerar otro cruce novedoso: la pluriparentalidad y las TRHA. El Código Civil y Comercial argentino, en el artículo 558, establece que una persona puede llegar a tener como máximo dos vínculos filiales simultáneos. Por ende, si se reclama una filiación en relación con una persona que tiene doble vínculo filial, ello importa dejar sin efecto una anteriormente establecida, ejerciendo la correspondiente acción de impugnación para efectuar el desplazamiento de la filiación existente (artículo 578).

No obstante, el avance de las TRHA visibilizó el deseo de personas que pretenden integran conformaciones filiales pluriparentales, donde más de dos personas tienen la voluntad de ser progenitores. Este tipo de conformaciones familiares ha tenido algunas expresiones jurídicas desde el derecho comparado. En Canadá, la ley de familia de la Columbia Británica del año 2013 admite la posibilidad jurídica de que un niño o niña tenga tres o más vínculos filiales, en casos de reproducción asistida, cuando ello haya sido así pactado previamente en un acuerdo escrito. ${ }^{39}$

\footnotetext{
${ }^{35}$ Conf. Herrera, Marisa y Salturi Amezcua, Martina, "Técnicas de reproducción humana asistida y responsabilidad civil", Revista La Ley, Buenos Aires, 2016.

${ }^{36}$ Revista de Doctrina y Jurisprudencia. Derecho de Familia nro. II, Abeledo Perrot, Buenos Aires, 2014, p. 257.

37 Herrera, Marisa y Salturi Amezcua, Martina, "Técnicas de reproducción humana asistida y responsabilidad civil", Revista La Ley, Buenos Aires, 2016.

${ }^{38}$ Herrera, Marisa y Salturi Amezcua, Martina, "Técnicas de reproducción humana asistida y responsabilidad civil", Revista La Ley, Buenos Aires, 2016.

39 "Family Law Act", Canadá. [Consulta: 22 de septiembre, 2016]. Disponible en: http://www.bclaws.ca/civix/document/id/complete/statreg/11025_00
} 
Por otra parte, en Brasil, la Cámara Civil Octava del Tribunal de Justicia del Estado de Río Grande, el doce de febrero de 2015, hizo lugar a una acción civil declaratoria de multiparentalidad iniciada por un matrimonio de mujeres y un amigo de ambas (donador del semen), quienes reclamaron a fin de poder llevar adelante un proyecto familiar conjunto en relación con una niña nacida en el marco de un "pacto de filiación" realizado entre ellos.

En Argentina, se han planteado dos casos similares en sede administrativa. En ambos se reconoce la triple filiación. El primero ocurrió en Mar del Plata, provincia de Buenos Aires, donde el Registro Provincial de las Personas, por disposición 2062 del 22 de marzo de 2015 resolvió constituir un triple vínculo filial respecto de un niño nacido por reproducción asistida. Esta técnica fue realizada por dos mujeres casadas con aporte de gametos masculinos de un amigo de ambas. En este caso, se hizo lugar a la solicitud de reconocimiento paterno solicitada respecto del niño de meses de vida, cuyo nacimiento ya se encontraba inscripto bajo la comaternidad del matrimonio de mujeres, y se adicionó el apellido paterno al nombre del niño.

El otro caso tuvo lugar en la ciudad de Buenos Aires. Se trataba de un supuesto similar al anterior, es decir la pretensión de multiparentalidad alegada por un matrimonio de mujeres, que ya figuraban registralmente como comadres del niño (de seis años de edad), y por un amigo de ambas (donador de los gametos masculinos) con voluntad de entablar también vínculo filial con el niño. Frente a ello, el Registro de Estado Civil y Capacidad de las Personas de la CABA procedió, en consecuencia, a la rectificación registral por triple filiación. Al nombre del niño se le adicionó el apellido paterno.

Estos casos recibieron algunas críticas por parte de la doctrina nacional, no en cuanto a la finalidad de la resolución, pero sí en cuanto a la forma. Se alegó "la inexistencia de facultades del órgano administrativo registral para arrogarse facultades jurisdiccionales e inaplicar las normas legales - de orden público-que imponían e imponen en el derecho argentino la regla de doble vínculo filial". ${ }^{40} \mathrm{Se}$ consideró que era una cuestión que debía dirimirse en la justicia.

Como podemos observar, la realidad en materia de proyectos parentales y familiares presenta nuevos desafíos jurídicos. No enfrentamos con la confluencia simultánea de más de dos voluntades procreacionales. Así, se visibiliza a la socioafectividad como elemento rupturista del derecho de familia contemporáne $0^{41} \mathrm{y}$ su vinculo con las TRHA.

\footnotetext{
${ }^{40}$ Herrera, Marisa, Manual de derecho de las familia, Buenos Aires, Abeledo Perrot, 2015, pp. 436-437.

${ }^{41}$ Cfr. HerRera, Marisa, "La noción de socioafectividad como elemento 'rupturista' del derecho de familia contemporáneo", Derecho de Familia. Revista Interdisciplinaria de Doctrina y Jurisprudencia, No. 66, Abeledo Perrot, 2014.
} 


\section{Cierre}

La incorporación de las TRHA como una tercera fuente filial es una de las grandes modificaciones previstas en el Código Civil y Comercial de la Nación. Con fundamento en los principios de realidad y pluralidad, este último garantiza el derecho de toda persona a vivir en una familia, conforme con su propio plan de vida, independientemente de su orientación sexual.

La presente adecuación del régimen filiatorio argentino a los principios fundamentales de derechos humanos acarrea mayor seguridad jurídica en las relaciones y legitima la conformación de diferentes tipos de familias. Como vimos, aún quedan algunas cuestiones por resolver en materia legislativa. Dos grandes cuentas pendientes son las figuras de la gestación por sustitución y la filiación post mortem. Al respecto, el ordenamiento jurídico argentino debe regularlas, puesto que el silencio trae inseguridad jurídica y la prohibición un alejamiento del derecho a la realidad. Estas prácticas se constatan fácticamente en el país, y han dado lugar a numerosos planteamientos judiciales.

Por lo tanto, consideramos que lo más adecuado es contar con una regulación específica y detallada que respete la perspectiva obligada de derechos humanos, y ofrezca reglas claras que protejan y garanticen los derechos en juego. No obstante, lo previsto en la norma para la filiación derivada de las TRHA, junto con la ley de acceso integral a las mismas, constituye un gran paso hacia el camino a una sociedad plural, inclusiva y respetuosa de los derechos de todas las personas.

\section{Bibliografía}

"Aplican el nuevo CCyC al ordenar la inscripción del nacimiento de un niño concebido mediante técnicas Icsı”, sAIJ. [Consulta: 25 de septiembre, 2016]. Disponible en: http://www.infojus.gob.ar/aplican-nuevo-ccyc-al-ordenar-inscripcion-nacimiento-nino-concebido-mediante-tecnicas-icsi-nv12407-2 015-08-13/123456789-0abc-704-21ti-lpssedadevon?utm_source=FacebookEtutm_medium=Social\&tutm_campaign=Jurisprudencia

Decreto 208/2015. "Registro del Estado Civil y Capacidad de las Personas. Modificación de las actas de matrimonio", saIJ. [Consulta: 22 de septiembre, 2016]. Disponible en: http://www.saij.gob.ar/registro-estado-civil-capacidad-personas-modificacion-actas-matrimonio-registro-estado-civil-capacidad-personas-modificacion-actas-matrimonio-nv12487-2015-06-01/123456789-0abc-784-21ti-lpssedadevon 
Díaz de Guijarro, EnRIQue, "La Voluntad y la responsabilidad procreacionales como fundamento de la determinación jurídica de la filiación”, Revista de Jurisprudencia Argentina La Ley, 1965.

Dirección del Registro Civil y Capacidad de las Personas, Manual para los oficiales públicos. [Consulta: 22 de septiembre, 2016]. Disponible en: http://www.jus.mendoza. gov.ar/documents/43978/172516/Nuevo+Codigo+Civil+-+Manual+para+los+oficiales+publicos.pdf/9b7fedb7-9dc8-4e40-9eef-931d729c2751

“Duras críticas al Registro Civil por no inscribir a una niña”, $L a$ Voz, 25 de octubre, 2015. [Consulta: 25 de septiembre, 2016]. Disponible en: http://www. lavoz.com.ar/ciudadanos/duras-criticas-al-registro-civil-por-no-inscribir-una-nina

"Family Law Act”, Canadá. [Consulta: 22 de septiembre, 2016]. Disponible en: http:// www.bclaws.ca/civix/document/id/complete/statreg/11025_00

“Guillermina Francesca ya tiene su partida de nacimiento”, Día a Día, 20 de octubre, 2015. [Consulta: 25 de septiembre, 2016]. Disponible en: http://www.diaadia. com.ar/cordoba/guillermina-francesca-ya-tiene-su-partida-de-nacimiento

Herrera, Marisa, “¿Cómo es la inscripción de los niños nacidos de técnicas de reproducción asistida?”. [Consulta: 22 de septiembre, 2016]. Disponible en: civil. com/wp-content/uploads/2016/04/2016-Inscripcion-de-nacimiento-reproduccio\%CC\%81n-asistida.pdf

Herrera, Marisa, "La noción de socioafectividad como elemento 'rupturista' del derecho de familia contemporáneo", Derecho de Familia. Revista Interdisciplinaria de Doctrina y Jurisprudencia, No. 66, Abeledo Perrot, 2014.

Herrera, Marisa, Manual de derecho de las familia, Buenos Aires, Abeledo Perrot, 2015.

Herrera, Marisa y Pellegrini, María Victoria, "El rol de los registros civiles en las relaciones de familia. Impacto del nuevo Código", Revista La Ley, 2015.

Herrera, Marisa y Salituri Amezcua, Martina, "Técnicas de reproducción humana asistida y responsabilidad civil”, Revista La Ley, Buenos Aires, 2016.

Kemelmajer de Carlucci, Herrera y Lloveras, "Tratado de derecho de familia”, según el Código Civil y Comercial 2014, tomo II, Argentina, Rubinzal - Culzoni.

Lamm, Eleonora, Rodríguez Iturburu, Mariana y Rubaja, Nieve, “Tecnicas de reproduccion humana asistida", en Aída Kemelmajer de Carlucci, Marisa Herrera y Nora Lloveras (dirs.), Tratado de Derecho de Familia, tomo V-A, Santa Fe, Rubinzal - Culzoni, 2016.

Ley 26.994, Boletín Oficial, 8 de octubre, 2014. [Consulta: 22 de diciembre, 2016]. Disponible en: http://servicios.infoleg.gob.ar/infolegInternet/verNorma. do?id=235975

Ley de matrimonio igualitario, 2010. Disponible en: http://www.psi.uba.ar/academica/carrerasdegrado/psicologia/sitios_catedras/electivas/816_rol_psicologo/material/unidad2/complementaria/ley_de_matrimonio_igualitario.pdf 
“'M. Y. M. y otros c. GCBA s/amparo' - Juzgado en lo Contencioso administrativo y Tributario No. 6 de la Ciudad Autónoma de Buenos Aires - 12/07/2011”, La Ley, 2011-D

“M.P.C. y otra c/GCBA s/medida cautelar' - Juzgado en lo Contencioso Administrativo y Tributario de la Ciudad Autónoma de Buenos Aires No. 4 - 07/04/2011". El Dial. Disponible en: http://www.eldial.com/nuevo/lite-jurisprudencia-detalle.asp?base $=14$ th $=$ uttid $=28303$

Ministerio de Justicia y Derechos Humanos, Ley 26.413. Disponible en: http://servicios. infoleg.gob.ar/infolegInternet/anexos/145000-149999/145345/texact.htm

Ministerio de Justicia y Derechos Humanos, Resolución 113/2015. [Consulta: 22 de septiembre, 2016]. Disponible en: http://boletinoficial.cba.gov.ar/wp-content/4p96humuzp/2015/12/161215_bocba_1stj9N19.pdf

PÉrez, Agustina, “Argumentos y contraargumentos en torno a la fertilización post mortem. ¿Qué tiene la maternidad/paternidad póstuma que incomoda tanto?", Revista de Derecho Privado y Comunitario, No. 2016-1, Rubinzal Culzoni, 2016.

“'V. A. F. y otros vs. Gobierno de la Ciudad Autónoma de Buenos Aires s. Amparo' Juzgado en lo Contencioso Administrativo y Tributario № 15 de la Ciudad Autónoma de Buenos Aires - 24/06/2011", Rubinzal.

Vázquez Acatto, Mariana, "Se hace camino al andar, el Código Civil y Comercial y la primera sentencia sobre técnicas de reproducción humana asistida", Revista de Derecho de Familia, vol. 1, No. 50, 2016

XXV Jornadas Nacionales de Derecho Civil, Bahía Blanca, 2015. [Consulta: 22 de septiembre, 2016]. Disponible en: http://jndcbahiablanca2015.com/wp-content/uploads/2015/10/CONCLUSIONES-06.pdf

Zeger-Hochschild, Fernando, Glosario de terminologia en técnicas de reproducción asistida, International Committee for Monitoring Assisted Reproductive Technology - Organización Mundial de la Salud, 2010. [Consulta: 21 de septiembre, 2016]. Disponible en: http://www.who.int/reproductivehealth/publications/infertility/art_terminology2/es/ 